\title{
SEISMIC RESPONSE OF MULTI-STOREY BUILDINGS INCORPORATING FLOATING COLUMNS
}

\author{
Nabeel Musthafa ${ }^{1}$, Annapurna B.P ${ }^{2}$ \\ ${ }^{I}$ PG Student, Structural Engineering, U.V.C.E, Karnataka, India \\ ${ }^{2}$ Associate Professor, Department of Civil Engineering, U.V.C.E, Karnataka, India
}

\begin{abstract}
Various factors which governs in contributing damage to the structure during an earthquake are vertical irregularities, irregularity in strength and stiffness, mass irregularity, torsional irregularity, etc. One such irregularity is a Floating Column configuration in a building. In this study, the influence of Floating columns on seismic response of multi-storey buildings is studied. Floating Column is basically a stubbed column which is stopped at a particular storey and does not have any continuity to the lower adjacent storey. Such Columns floating in the structure definitely bring out aesthetics of the building. But when such a column become an active member in resisting and dissipating the lateral forces due to seismicity, a hindrance is created in the clear load path and thereby generating a weak link in the structure. The present work focuses on the seismic behaviour of buildings, i.e., the effect on Lateral Displacement and Storey drift when Floating Columns are introduced in the structure. The Floating columns are varied in numbers and at various locations in plan. The transfer girders are varied in sizes (making it safe against the loads) and are compared with its regular counterpart. It is observed that by introducing Floating Columns into the framed structure, the criticality of the structure increases in terms of storey drift. Conclusions drawn from the study stipulates that introducing Floating Columns increases the criticality of the structure under seismic forces.
\end{abstract}

\section{KeyWords: Floating Column, Transfer Girder, Storey Drift, Displacement, Response Spectrum}

\section{INTRODUCTION}

During past earthquakes, reinforced concrete (RC) buildings have been damaged on a very large scale. A wide range of structural damages observed during past earthquakes across the world has been very educative in identifying the cause of failure. The principal causes of damage to RC buildings are soft storey, floating columns, mass irregularities, inconsistent seismic performance, soil and foundation effect, pounding of adjacent structures and inadequate ductile detailing of members.

Column is basically a vertical member in a framed structure which transfers the loads from beams and slabs to the foundation. Columns usually runs throughout the building from the foundation level to the top most storey of a building to function in transferring the loads to the foundation effectively. At any circumstance, a column is stopped or stubbed at any storey without any continuity to the adjacent lower storey which may be due to architectural requirements or site constraints, such a column hanging on the floors above, resting on transfer girders is referred to as Floating Column.

Although the feature of Floating columns can be marvelously beautiful with regards to architectural perception and may bring out the aesthetics of the structure to a new level, such configurations of Floating columns resting on transfer girders can be hazardous in a high seismicity region.

Though floating columns have to be discouraged, there are many projects in which they are adopted, especially above the ground floor, where transfer girders are employed, so that more open space is available in the Ground Floor.Hence, it is of importance to study the behaviour of structures or buildings in particular that incorporates Floating Columns in its structural frame.

Floating Columns not only creates huge moments and forces on to the transfer girders but they tend to generate a discontinuity in the distribution of the forces making the structure vulnerable to damage and prone to collapse.

\section{LITERATURE REVIEW}

Khandve V Amit [1] carried out investigation on importance of explicitly recognizing the presence of the open storey in the analysis of the building. The seismic vulnerability of buildings with soft first storey was shown through an example building. The drift and the strength demands in the first storey columns were very large for buildings with soft ground stories. Alternative measures need to be adopted for this specific situation. The under-lying principle of any solution to this problem is in (a) increasing the stiffness of the first storey such that the first storey is at least $50 \%$ as stiff as the second storey, i.e., soft first stories are to be avoided, and (b) providing adequate lateral strength in the first storey.

Sharma A. and Bhadra B. [2] analysed the performance of vertically irregular RC frames under seismicity. Response Spectrum Analysis and Time History analysis were considered for the study. Three types of irregularities namely, mass, stiffness and vertical geometry irregularity were incorporated in the study. The authors understood that the storey shear forces tends to be maximum for the first storey 
and decreases at higher stories. It was concluded that mass irregular building experiences larger base shear and stiffness irregular building experiences lesser base shear than the regular building. The lateral displacements displayed by vertically irregular buildings were found to be greater than the regular building displacements. It was concluded that lower stiffness results in higher displacements at higher stories.

Soni P. Devesh and Mistry B. Bharat [3] summarized the seismic response of vertically irregular building frames. A review of studies on the seismic behaviour of vertically irregular structures along with their findings was presented. It was observed that building codes provide criteria to classify the vertically irregular structures and suggest dynamic analysis to arrive at design lateral forces. Most of the studies agree on the increase in drift demand in the tower portion of set-back structures and on the increase in seismic demand for buildings with discontinuous distributions in mass, stiffness, and strength.

\section{METHODOLOGY}

A 5-storied structure with a typical storey height of $3 \mathrm{~m}$ is considered as the basic structural model. The building consists of $3 \times 3$ bays, each bay spacing being $5 \mathrm{~m}$ in both $\mathrm{X}$ and $\mathrm{Y}$ - directions. The general plan and three dimensional view of frames at typical floor level is as shown in figure 1. This model is considered as the Regular model and will be denoted as REG model. The characteristics and properties of the Regular model are as follows:

- Cross-sectional Properties

$\begin{array}{ll}\text { Number of storeys } & : 5 \text { storeys }(\mathrm{H}=15 \mathrm{~m}) \\ \text { Height of typical floor } & : 3 \mathrm{~m} \\ \text { Column size } & : 450 \times 450 \mathrm{~mm} \\ \text { Beam size } & : 230 \times 300 \mathrm{~mm} \\ \text { Slab thickness } & : 150 \mathrm{~mm} \\ \text { Masonry Wall thickness } & : 230 \mathrm{~mm}\end{array}$

- Material and Seismic Properties

$\begin{array}{ll}\text { Characteristic strength of concrete } & : 25 \mathrm{MPa} \\ \text { Grade of steel } & : 415 \mathrm{MPa} \\ \text { Density of concrete } & : 25 \mathrm{kN} / \mathrm{m}^{3} \\ \text { Modulus of Elasticity of concrete } & : 25000 \times 10^{3} \\ \mathrm{kN} / \mathrm{m}^{2} & \\ \text { Poisson's ratio of concrete } & : 0.2 \\ \text { Earthquake Zone } & : \text { III } \\ \text { Importance factor } & : 1.00 \\ \text { Response Reduction factor } & : 5 \\ \text { Damping ratio } & : 5 \%\end{array}$

The structural systems are subjected to 4 types of Primary Load cases as per provisions of Indian Standard Code of Practice for structural safety of buildings- Loading standards IS-875-1987 Part I and II. Methods of analysis considered for the present study are Static Equivalent method of analysis and Dynamic Response Spectrum Analysis. The loads are as follows:

- Dead Load case (Gravity load), denoted as DL

- Live Load case (Vertical load), denoted as LL
- Equivalent Static Lateral Force in X-direction (Earthquake), denoted as EQX

- Equivalent Static Lateral Force in Y-direction (Earthquake), denoted as EQY

- $\quad$ Response Spectra in X-direction, denoted as RSX

- $\quad$ Response Spectra in Y-direction, denoted as RSY

The Dead load consists of self-weight of structural elements and wall load. In the seismic weightcalculations, only $25 \%$ of the floor live load is considered.

a) Dead Loads

Floor finish $\quad: 1 \mathrm{kN} / \mathrm{m}^{2}$

Wall load $\quad:(3-0.3) * .23 * 18.1=$

$11.26 \mathrm{kN} / \mathrm{m}$

Partition wall load $: 1 \mathrm{kN} / \mathrm{m}^{2}$

b) Live loads

$\begin{array}{ll}\text { On typical floors } & : 3 \mathrm{kN} / \mathrm{m}^{2} \\ \text { On roof } & : 1.5 \mathrm{kN} / \mathrm{m}^{2}\end{array}$
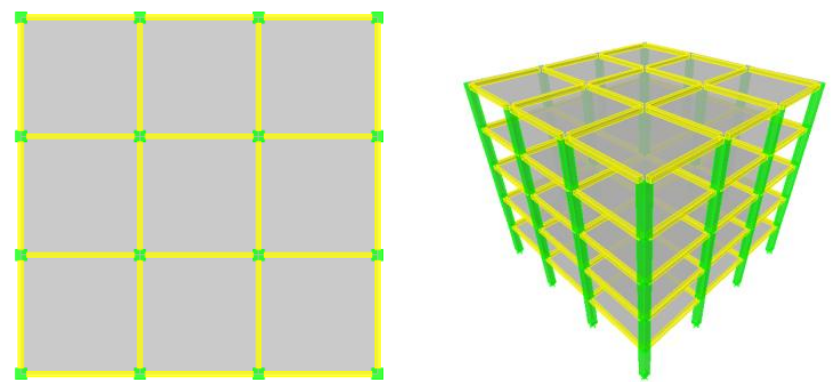

Fig -1: General Plan and 3-D view of Regular building considered

The irregular models with Floating Columns (FC) are basically categorized as models with One, Two and Four Floating Columns. The subtypes ' $\mathrm{E}$ ' and ' $\mathrm{M}$ ' indicates the positions of $\mathrm{FC}$ at the end and middle of the building, respectively. The subtype- ' $A$ ' indicates models with Transfer girder size as $230 \times 300 \mathrm{~mm}$ and subtype ' $\mathrm{B}$ ' with incremented sizes of transfer girder to make it safe against all the loads mentioned in the previous section.

- Models with One Floating Column (1FC)

i) 1FCE-A- One FC is located at the extreme end of an exterior frame with transfer girder size-230x300mm. Refer fig 2(a)

ii) 1 FCE-B- One FC is located at the extreme end of an exterior frame with transfer girder size-700x700 mm. Refer fig 2(b)

iii) 1FCM-A- One FC is located in between the ends of an interior frame with transfer girder size-230x300 mm. Refer fig 2(c)

iv) 1FCM-B- One FC is located in between the ends of an interior frame with transfer girder size-700x700 mm. Refer fig 2(d)

- Models with Two Floating Columns (2FC)

v) 2FCEO-A- Two Floating Columns are located at the corners of two exterior frames diagonally opposite to each other with Transfer girder size-230x300 mm. Refer fig 2(e)

vi) 2FCEO-B- Two Floating Columns are located at the corners of two exterior frames 
diagonally opposite to each other with Transfer girder size-750x750 mm. Refer fig 2(f)

vii) 2 FCE-A- Two Floating Columns are located at the corners of a single exterior frame with Transfer girder size-230x300 mm. Refer fig 2(g)

viii) 2FCE-B- Two Floating Columns are located at the corners of a single exterior frame with Transfer girder size-750x750 mm. Refer fig 2(h)

ix) 2FCM-A- Two Floating Columns are located in between the ends of a single interior frame with transfer girder size230x300 mm. Refer fig 2(i)

x) 2FCM-B- Two Floating Columns are located in between the ends of a single interior frame with transfer girder size750x750 mm. Refer fig 2(j)

- Models with Four Floating Columns (4FC)

xi) 4FCE-A- Four Floating Columns are located at the corners of two exterior frames with transfer girder size-230x300 mm. Refer fig 2(k)

xii) 4FCE-B- Four Floating Columns are located at the corners of two exterior frames with transfer girder size-1000x1000 mm. Refer fig 2(1)

xiii) 4FCM-A- Four Floating Columns are located in between the ends of two interior frames, i.e., two floating columns in each frame frames with transfer girder size230x300 mm. Refer fig 2(m)

xiv) 4FCM-B- Four Floating Columns are located in between the ends of two interior frames, i.e., two floating columns in each frame frames with transfer girder size1000x1000 mm. Refer fig 2(n)

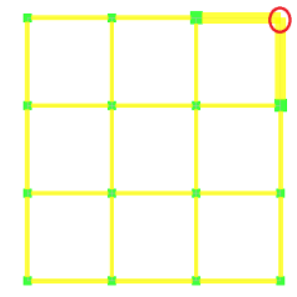

(a) Model 1FCE-A

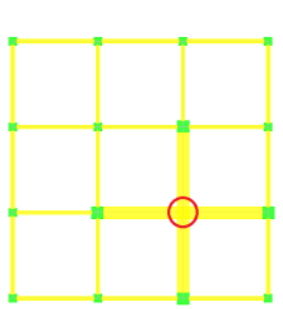

(d) Model 1FCM-B

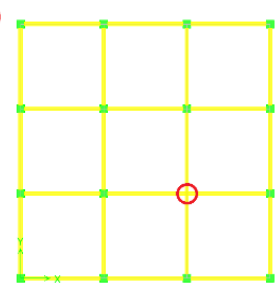

(b) Model 1FCE-B

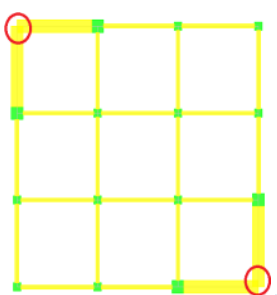

(e) Model 2FCEO-A

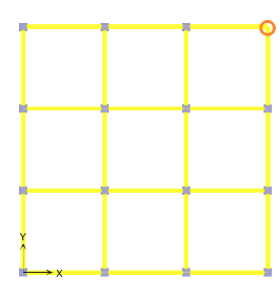

(c) Model 1FCM-A

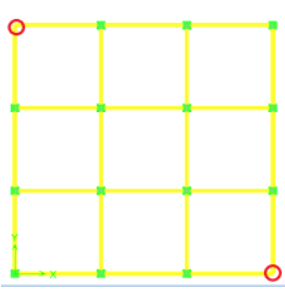

(f) Model 2FCEO-B

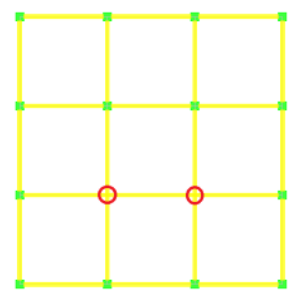

(g) Model 2FCE-A

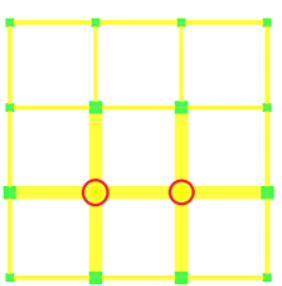

(j) Model 2FCM-B

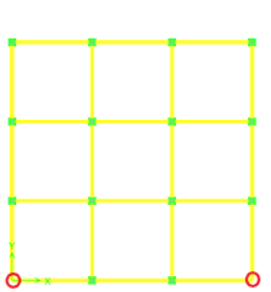

(h) Model 2FCE-B

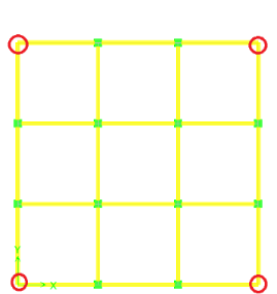

(k) Model 4FCE-A

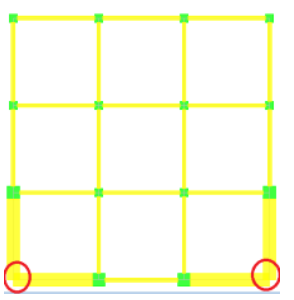

(i) Model 2FCM-A

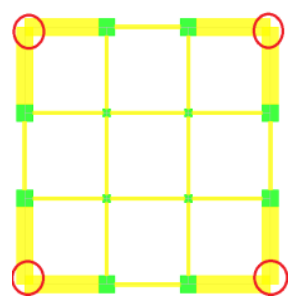

(I) Model 4FCE-B

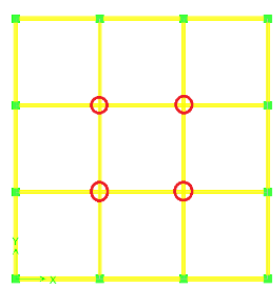

(m) Model 4FCM-A

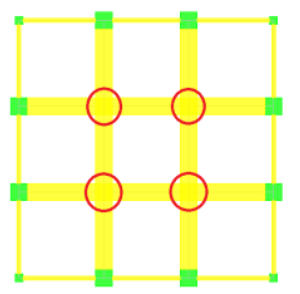

(n) Model 4FCM-B
Fig -2: Plan of building (models) showing location of Floating Columns and Transfer Girders

The sizes of the Transfer Girders are increased to make the particular Girder safe against all the loads mentioned in the previous section. Any cross-sections of Transfer Girder lesser than the sizes mentioned in sub-type 'B' of all models would lead to its failure for the model under consideration.

For the present investigation, the Floating columns for various models are placed at the 1 st storey level. The elevation of models with Floating columns placed in 1st storey is as shown in fig 3

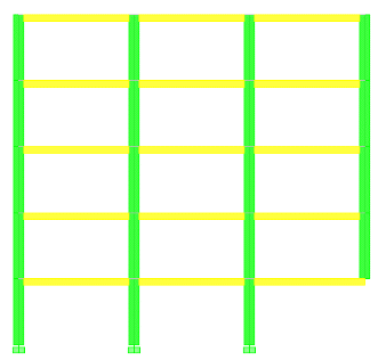

Fig -3: Elevation of building showing position of FC at 1st storey level

\section{RESULTS \& DISCUSSIONS}

\subsection{Storey Drift}

The Storey Drift obtained from seismic analysis for different models are presented here. The drift obtained from Equivalent Static Load case (EQX) and Response Spectrum 
Load case (RSX) are incorporated.It was observed that buildings with FC at the bottom most storey displays larger storey drifts w.r.t. buildings with FC at higher stories. Hence, models with FC at the bottom most storey (1st storey) are considered for the present investigation.The effects of location and the number of FC at 1st storey and Transfer girder position on Storey drift of models is studied. All the models described in fig 2 with FC at the 1st storey are considered. The storey drift variation due to position and number of FC at the 1st storey is depicted in figures 4 to 10 and tables I to VII.

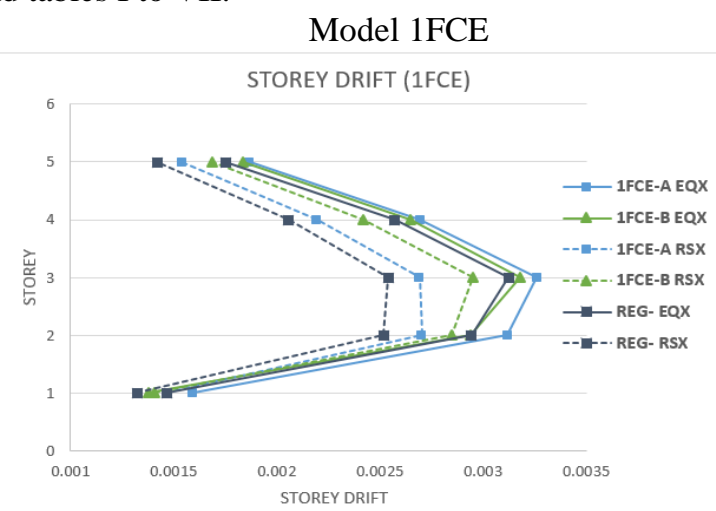

Fig -4: Comparison of Storey Drift of models 1FCE-A \& 1FCE-B

Table -1: Comparison of maximum Storey Drift for EQX and RSX load cases

\begin{tabular}{|l|l|l|}
\hline MAX. STOREY DRIFT-1FCE \\
\hline MODEL & EQX & RSX \\
\hline 1FCE-A & 0.003261 & 0.002702 \\
\hline 1FCE-B & 0.003182 & 0.002951 \\
\hline REGULAR & 0.003124 & 0.002541 \\
\hline
\end{tabular}

It is seen from fig 4 and table 1 that due to the introduction of transfer girder with larger cross-section in 1FCE-B, the storey drift reduces by $2.5 \%$ w.r.t 1 FCE-A considering EQX load case. But the above statement contradicts the behaviour of model 1FCE-B under RSX loading. Considering RSX, the drift in 1FCE-B increases by $9.2 \%$ w.r.t 1FCE-A. Due to the introduction of heavy transfer girder in 1FCE-B, the drift decreases under static analysis of EQX and increases under dynamic analysis of RSX. 1FCE-B displays $1.86 \%$ and $16.1 \%$ larger drift than the Regular model under both static (EQX) and dynamic (RSX) analyses.

\section{- Model 1FCM}

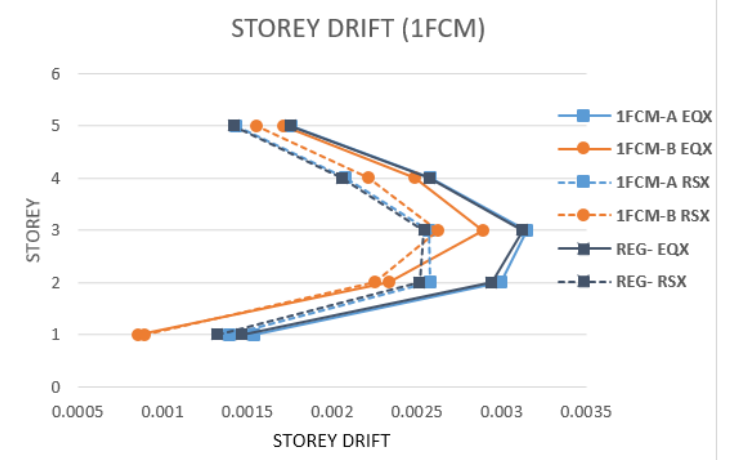

Fig -5: Comparison of Storey Drift of models 1FCM-A \& 1FCM-B
Table -2:Comparison of maximum Storey Drift for EQX and RSX load cases

\begin{tabular}{|l|l|l|}
\hline \multicolumn{4}{|l|}{ MAX. STOREY DRIFT-1FCM } \\
\hline MODEL & EQX & RSX \\
\hline 1FCM-A & 0.003146 & 0.002577 \\
\hline 1FCM-B & 0.002888 & 0.002621 \\
\hline REGULAR & 0.003124 & 0.002541 \\
\hline
\end{tabular}

It is seen from fig 5 and table 2 that due to the introduction of transfer girder with larger cross-section in 1FCM-B, the storey drift reduces by $8.94 \%$ w.r.t 1 FCM-A considering EQX load case. Considering RSX, the drift in 1FCM-B increases by $1.7 \%$ w.r.t $1 \mathrm{FCM}-\mathrm{A}$. Due to the introduction of heavy transfer girder in $1 \mathrm{FCM}-\mathrm{B}$, the drift decreases under static analysis of EQX and increases under dynamic analysis of RSX. 1FCM-B displays $3.15 \%$ larger drift than the Regular model under dynamic analysis (RSX). While considering static analysis (EQX), 1FCM-B shows $8.17 \%$ lesser drift than the Regular model.

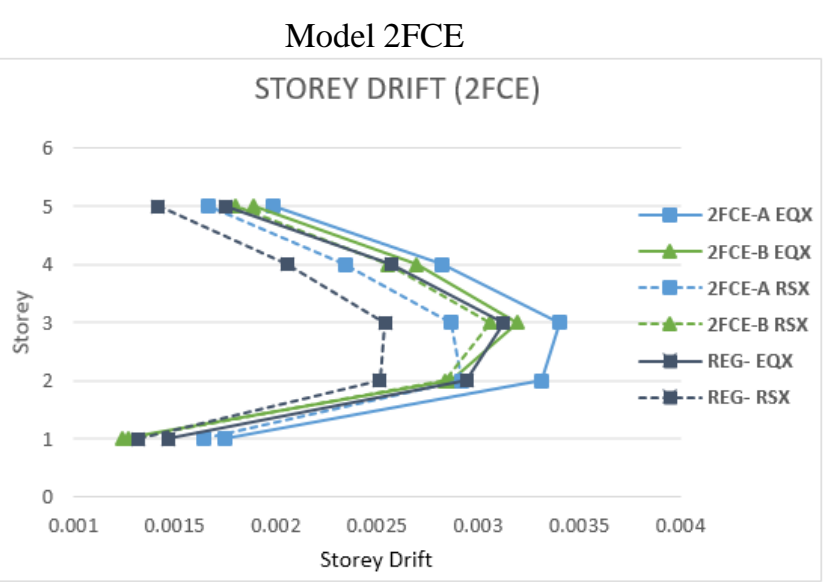

Fig -6: Comparison of Storey Drift of models 2FCE-A \& 2FCE-B

Table -3: Comparison of maximum Storey Drift for EQX and RSX load cases

\begin{tabular}{|l|l|l|}
\hline MAX. STOREY DRIFT-2FCE \\
\hline MODEL & EQX & RSX \\
\hline 2FCE-A & 0.003406 & 0.002922 \\
\hline 2FCE-B & 0.003192 & 0.003063 \\
\hline REGULAR & 0.003124 & 0.002541 \\
\hline
\end{tabular}

It is seen from fig 6 and table 3 that due to the introduction of transfer girder with larger cross-section in 2FCE-B, the storey drift reduces by $6.7 \%$ w.r.t $2 \mathrm{FCE}-\mathrm{A}$ considering EQX load case. Considering RSX, the drift in 2FCE-B increases by $4.83 \%$ w.r.t 2FCE-A. Due to the introduction of heavy transfer girder in 2FCE-B, the drift decreases under static analysis of EQX and increases under dynamic analysis of RSX. 2FCE-B displays $2.18 \%$ and $20.54 \%$ larger drift than the Regular model under static (EQX) and dynamic (RSX) analyses, respectively. 
- Model 2FCEO

\section{STOREY DRIFT (2FCEO)}

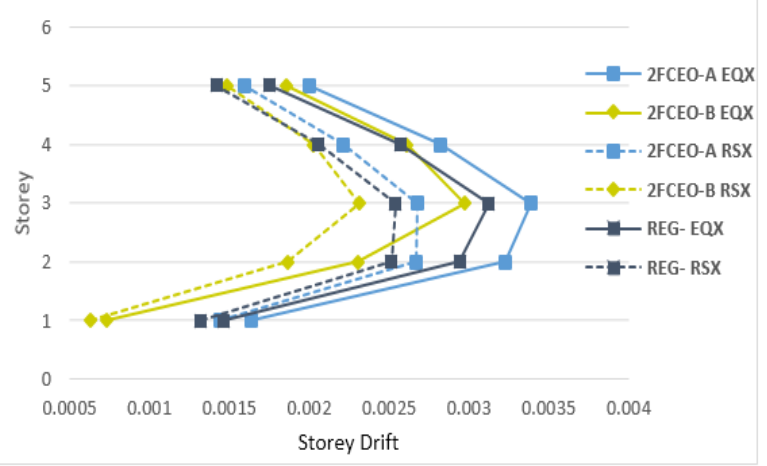

Fig-7: Comparison of Storey Drift of models 2FCEO-A \& 2FCEO-B

Table -4: Comparison of maximum Storey Drift for EQX and RSX load cases

\begin{tabular}{|l|l|l|}
\hline MAX. STOREY DRIFT-2FCEO \\
\hline MODEL & EQX & RSX \\
\hline 2FCEO-A & 0.003385 & 0.002674 \\
\hline 2FCEO-B & 0.002975 & 0.002314 \\
\hline REGULAR & 0.003124 & 0.002541 \\
\hline
\end{tabular}

It is seen from fig 7 and table 4 that due to the introduction of transfer girder with larger cross-section in 2FCEO-B, the storey drift reduces by $13.78 \%$ w.r.t 2 FCEO-A considering EQX load case. Considering RSX, the drift in 2FCEO-B decreases by $15.56 \%$ w.r.t 2 FCEO-A. Due to the introduction of heavy transfer girder in 2FCEO-B, the drift decreases under static and dynamic analyses, i.e., EQX and RSX. 2FCEO-B displays 5.0\% and $9.81 \%$ lesser drift than Regular model under static (EQX) and dynamic (RSX) analyses, respectively.

- $\quad$ Model 2FCM

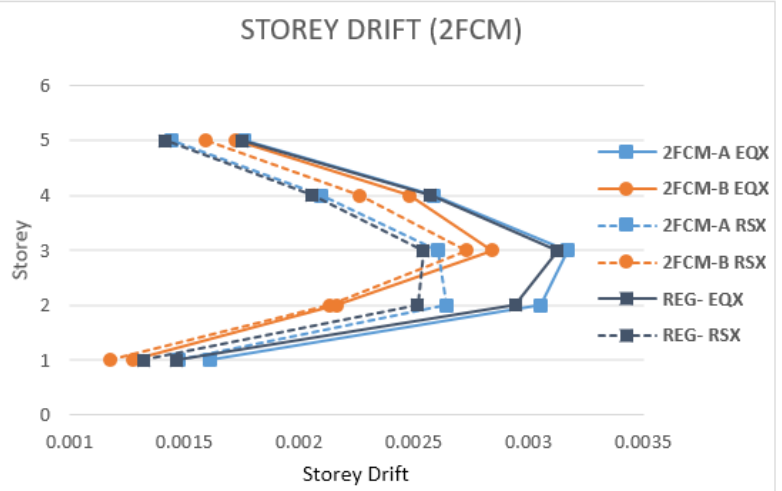

Fig -8: Comparison of Storey Drift of models 2FCM-A \& 2FCM-B

Table -5: Comparison of maximum Storey Drift for EQX and RSX load cases

\begin{tabular}{|l|l|l|}
\hline MAX. STOREY DRIFT-2FCM \\
\hline MODEL & EQX & RSX \\
\hline 2FCM-A & 0.003169 & 0.002641 \\
\hline 2FCM-B & 0.002842 & 0.002727 \\
\hline REGULAR & 0.003124 & 0.002541 \\
\hline
\end{tabular}

It is seen from fig 8 and table 5 that due to the introduction of transfer girder with larger cross-section in 2FCM-B, the storey drift reduces by $11.5 \%$ w.r.t $2 \mathrm{FCM}$-A considering EQX load case. Considering RSX, the drift in 2FCM-B increases by $3.25 \%$ w.r.t 2 FCM-A. Due to the introduction of heavy transfer girder in 2FCM-B, the drift decreases under static analysis of EQX and increases under dynamic analysis of RSX. 2FCM-B displays $7.32 \%$ larger drift thanthe Regular model under dynamic analysis (RSX). While considering static analysis (EQX), 2FCM-B shows $9.92 \%$ lesser drift than Regular model.

\section{- $\quad$ Model 4FCE}

\section{STOREY DRIFT(4FCE)}

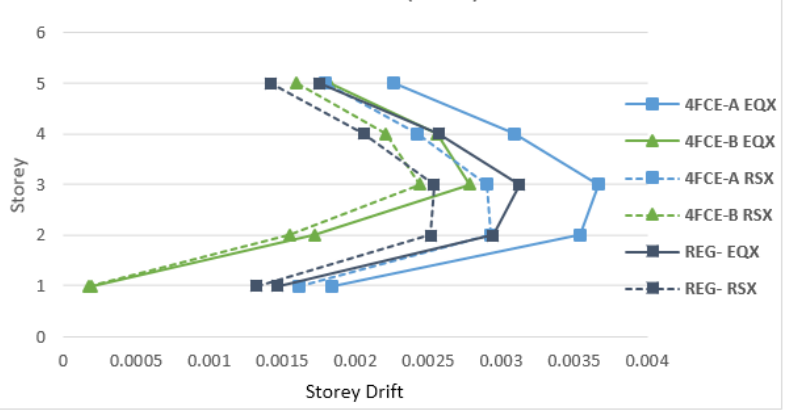

Fig -9: Comparison of Storey Drift of models 4FCE-A \& 4FCE-B

Table -6: Comparison of maximum Storey Drift for EQX and RSX load cases

\begin{tabular}{|l|l|l|}
\hline MAX. STOREY DRIFT-4FCE \\
\hline MODEL & EQX & RSX \\
\hline 4FCE-A & 0.003664 & 0.002925 \\
\hline 4FCE-B & 0.002785 & 0.002441 \\
\hline REGULAR & 0.003124 & 0.002541 \\
\hline
\end{tabular}

It is seen from fig 9 and table 6 that due to the introduction of transfer girder with larger cross-section in 4FCE-B, the storey drift reduces by $31.56 \%$ w.r.t 4 FCE-A considering EQX load case. Considering RSX, the drift in 4FCE-B decreases by $19.83 \%$ w.r.t 4 FCE-A. Due to the introduction of heavy transfer girder in 4FCE-B, the drift decreases under both static and dynamic analysis, i.e., EQX and RSX. 4FCEB displays $12.17 \%$ and $4.1 \%$ lesser drift than Regular model under both static (EQX) and dynamic (RSX) analyses.

- Model 4FCM

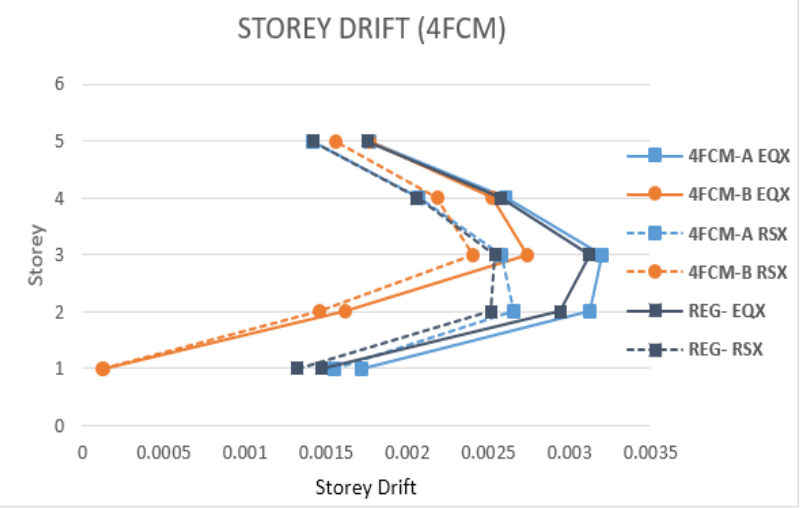

Fig -10: Comparison of Storey Drift of models 4FCM-A \& 4FCM-B 
Table -7: Comparison of maximum Storey Drift for EQX and RSX load cases

\begin{tabular}{|l|l|l|}
\hline \multicolumn{4}{|l|}{ MAX. STOREY DRIFT-4FCM } \\
\hline MODEL & EQX & RSX \\
\hline 4FCM-A & 0.003197 & 0.002652 \\
\hline 4FCM-B & 0.002737 & 0.002402 \\
\hline REGULAR & 0.003124 & 0.002541 \\
\hline
\end{tabular}

It is seen from fig 10 and table 7 that due to the introduction of transfer girder with larger cross-section in 4FCM-B, the storey drift reduces by $16.8 \%$ w.r.t $4 \mathrm{FCM}-\mathrm{A}$ considering EQX load case. Considering RSX, the drift in 4FCM-B decreases by $10.4 \%$ w.r.t 4 FCM-A. Due to the introduction of heavy transfer girder in $4 \mathrm{FCM}-\mathrm{B}$, the drift decreases under static and dynamic analysis, i.e., EQX and RSX. 4FCM-B displays $14.14 \%$ and $5.79 \%$ lesser drift than Regular model under both static (EQX) and dynamic (RSX) analyses.

\subsection{Lateral Displacement}

The Lateral Displacement obtained from seismic analysis for different models are presented here. The displacement obtained from Equivalent Static Load case (EQX) and Response Spectrum Load case (RSX) are incorporated.The effects of location and the number of FC at 1st storey and Transfer girder position on Lateral Displacement of models is studied. All the models described in fig 2 with FC at the 1 st storey are considered. The Lateral Displacement variation due to position and number of FC at the 1st storey is depicted in figures 11 to 13 and tables 8 to 10 .

\section{- $\quad$ Model 1FC}

Here, models with one Floating Column at different locations in plan at 1st storey for Earthquake Zone III are studied. The models taken into account are: 1FCE, 1FCEM and 1FCM.

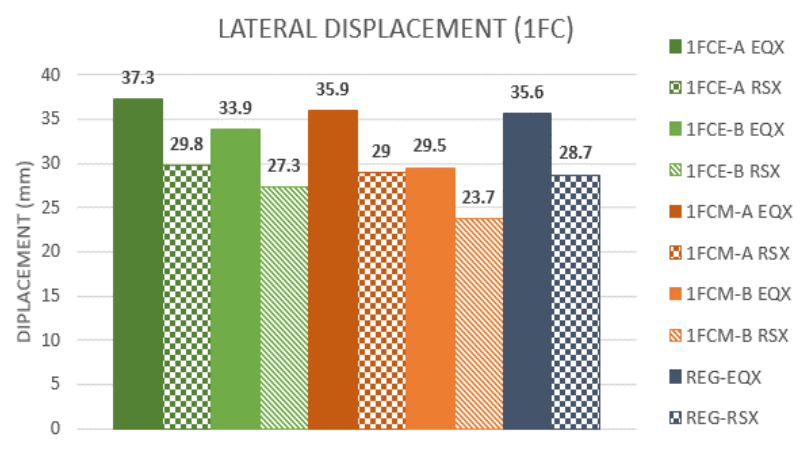

Fig -11: Comparison of Displacement of models with 1FC

Table -8: Comparison of maximum Lateral Displacement for EQX and RSX load cases

\begin{tabular}{|l|l|l|}
\hline LATERAL DISPLACEMENT-1FC \\
\hline MODEL & EQX & RSX \\
\hline 1FCE-A & 37.3 & 29.8 \\
\hline 1FCE-B & 33.9 & 27.3 \\
\hline 1FCM-A & 35.9 & 29.0 \\
\hline 1FCM-B & 29.5 & 23.7 \\
\hline REGULAR & 35.6 & 28.7 \\
\hline
\end{tabular}

It is seen from fig 11 and table 8 that model1FCE displays the largest displacement w.r.t models with one FC. Both the models 1FCE- A \& B shows greater displacement than 1FCM-A \& B. It can be observed that due to the introduction heavy transfer girder the lateral displacement reduces w.r.t to REG model.

- Model 2FC

Here, models with two Floating Columns at different locations in plan at 1st storey for Earthquake Zone III are studied. The models taken into account are: 2FCE, 2FCEO and 2FCM.

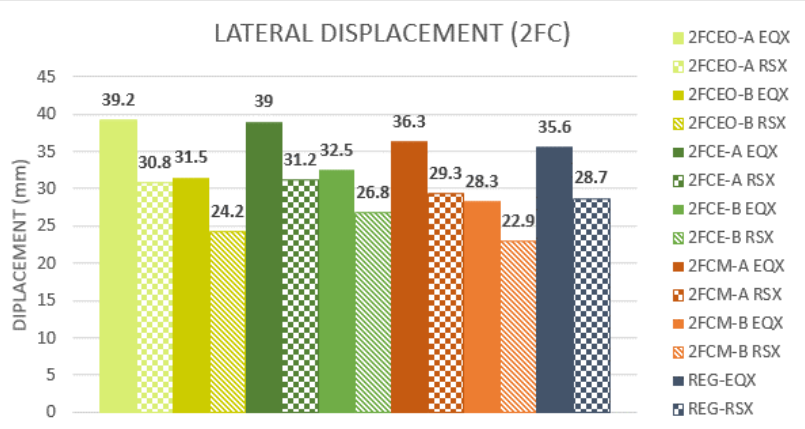

Fig -12: Comparison of Displacement of models with 2FC

Table -9: Comparison of maximum Lateral Displacement for EQX and RSX load cases

\begin{tabular}{|l|l|l|}
\hline \multicolumn{2}{|l|}{ LATERAL DISPLACEMENT-2FC } \\
\hline MODEL & EQX & RSX \\
\hline 2FCEO-A & 39.2 & 30.8 \\
\hline 2FCEO-B & 31.5 & 24.2 \\
\hline 2FCE-A & 39.0 & 31.2 \\
\hline 2FCE-B & 32.5 & 26.8 \\
\hline 2FCM-A & 36.3 & 29.3 \\
\hline 2FCM-B & 28.3 & 22.9 \\
\hline REGULAR & 35.6 & 28.7 \\
\hline
\end{tabular}

It is seen from fig 12 and table 9 that models 2FCE displays the largest displacement under EQX and RSX analyses for both the sub-types A and B.It can be observed that due to the introduction heavy transfer girder the lateral displacement reduces w.r.t to REG model.

\section{- $\quad$ Model 4FC}

Here, models with four Floating Columns at different locations in plan at 1 st storey for Earthquake Zone III are studied. The models taken into account are: 4FCE and 4FCM. 


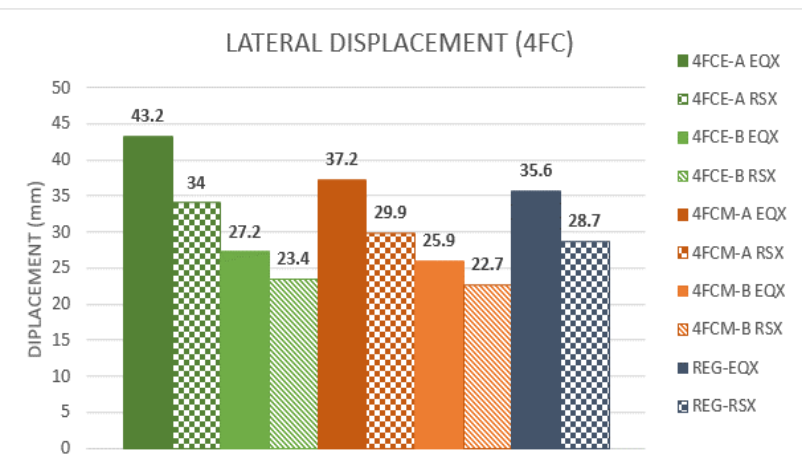

Fig -13: Comparison of Displacement of models with 4FC

Table -10: Comparison of maximum Lateral Displacement for EQX and RSX load cases

\begin{tabular}{|l|l|l|}
\hline \multicolumn{3}{|l|}{ LATERAL DISPLACEMENT-4FC } \\
\hline MODEL & EQX & RSX \\
\hline 4FCE-A & 43.2 & 34 \\
\hline 4FCE-B & 27.2 & 23.4 \\
\hline 4FCM-A & 37.2 & 29.9 \\
\hline 4FCM-B & 25.9 & 22.7 \\
\hline REGULAR & 35.6 & 28.7 \\
\hline
\end{tabular}

It is seen from fig 12 and table 9 that models 4FCE displays the largest displacement under EQX and RSX analyses for both the sub-types A and B. It can be observed that due to the introduction heavy transfer girder the lateral displacement reduces w.r.t to REG model.

The observations from the results obtained are summarized below:

[1] Maximum lateral displacements and storey drifts are observed in models 1FCE-B, 2FCE-B and 4FCE-B among models having one, two and four Floating columns respectively. Hence, these locations are critical for Floating Columns to exist. Therefore, it can be generalized that when floating columns are located at the extreme ends of a building, criticality increases due to increase in storey drift and displacement.

[2] Storey drift and Lateral displacement in models 1FCM-B, 2FCM-B and 4FCM-B are found to be the least among models having one, two and four Floating columns respectively. Hence, it can be stated that these models are least critical or the safest when drift and drift are considered as the parameters. Therefore, it can be generalized that when floating columns are positioned at the interior of a building, criticality decreases due to lesser drift and displacement.

[3] The introduction of transfer girder with larger crosssection tends to reduce the maximum inter-storey drift and lateral displacement in all the models w.r.to models without increment in the transfer girder size under static Equivalent method of analysis (EQX).

[4] When dynamic analysis (RSX) is performed, the maximum storey drift for models 2FCEO, 4FCE, 4FCEM and 4FCM tends to reduce due to the introduction of transfer girder with larger cross-sections (B) w.r.t models without increment in the transfer girder size (A).
[5] For models 1FCE, 1FCEM, 1FCM, 2FCE and 2FCM, the inter-storey drift increases due to the introduction of transfer girder with larger cross-sections (B) w.r.t models without increment in the transfer girder size (A) when dynamic analysis (RSX) is performed.

[6] Hence, it can be concluded that when the building is asymmetric in plan, the storey drift increases due to the introduction of transfer girder with larger cross-sections. Wherein the building is symmetric in plan, the inter-storey drift tends to reduce due to the introduction of transfer girder with larger cross-sections under Dynamic Analysis

[7] Criticality of a building with Floating Column is relatively dependent on the symmetry of the structure. Buildings with lesser symmetry (asymmetric in plan or asymmetry due to location of floating column) attract larger drifts than its symmetric counterparts, thereby increasing the criticality and vice versa.

[8] It can be observed that Storey Drifts obtained from Equivalent Static method (EQX) for models 1FCE-B, 1FCM$\mathrm{B}, 2 \mathrm{FCE}-\mathrm{B}$ and 2FCM-B shows a reduction in drift values w.r.t. their ' $A$ ' subtype models. While storey drift obtained from Response Spectrum analysis (RSX) shows an increment in drift values. It is fairly noticeable that dynamic analysis contradicts static analysis results. Since, the Response Spectrum method gives realistic values as the nature of analysis is dynamic, buildings with FC irregularity should be analysed with dynamic analysis.

\section{CONCLUSIONS}

The conclusions drawn from both static and dynamic analyses is that the location of Floating columns in plan determines the criticality of the structure under seismicity. Greater the number of Floating columns in the framed elements, greater would be the cross-sectional sizes of the Transfer girders. Buildings incorporating FC with symmetry displays lesser drift and displacement w.r.t. its asymmetric counterparts. Hence, under unavoidable conditions where FC configuration is imperative, it is better to utilize symmetry to reduce the effects of Floating Columns on Storey drift criteria. Therefore, proper analysis (preferably dynamic analysis) should be performed to determine the behaviour of such structures in earthquake prone areas.

\section{ACKNOWLEDGEMENT}

We sincerely thank \& acknowledge University Visvesvaraya College of Engineering, Bangalore University, Bangalore for the support, guidance \& co-operation extended for the successful completion of this study.

\section{REFERENCES}

[1] Khandve V. Amit (2012), "Seismic Response of RC Frame Buildings with Soft Storeys", International Journal of Engineering Research and Applications, Vol. 2, Issue 3, May-June 2012, pp: 2100-2108

[2] Sharma A. \& Bhadra B. (2013), "Seismic Analysis and Design of Vertically Irregular RC Building Frames", 
Department of Civil Engneering, National Institute of Technology, Rourkela

[3] Soni P. Devesh et.al (2006), "Qualitative Review of Seismic Response of Vertically Irregular Building Frames", pp:121-132, ISET Journal of Earthquake Technology, Vol.43, December 2006

[4] Pankaj Agarwal and Manish Shrikhande, "Earthquake Resistant Design of Structures", PHI Learning Private Limited, 2006

\section{BIOGRAPHIES}

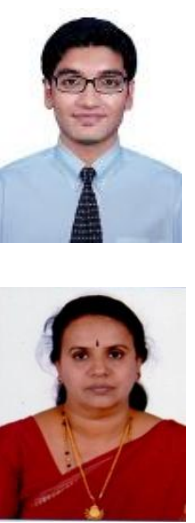

NabeelMusthafa is currently pursuing Masters in Structural Engineering in University Visvesvaraya College of Engineering, Bangalore. Key areas of research includes Effects of Irregularity in building under Seismicity.

Dr. Annapurna B.P. is currently Associate Professor in Department of Civil Engineering, University Visvesvaraya College of Engineering. Has vast experience in research and teaching for about 20 years. Key areas of research includes Seismic Performance of Irregular Buildings \& Strength and Durability aspects of Concrete using industrial waste-bio degradable and non-degradable waste. 